\title{
BADANGAM: An indigenized multi-grade teaching model
}

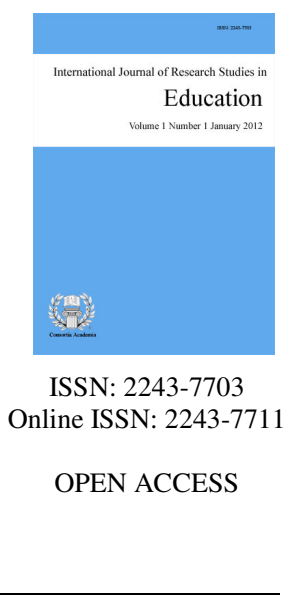

Velasco, Rustom A. $\bowtie$

Libang Elementary School, Philippines (velascorustom9@gmail.com)

Ramos, Allan O.

Ilocos Sur Polytechnic State College, Philippines (gstagudin2020.2@gmail.com)

Azarias, Ranec A.

Ilocos Sur Polytechnic State College, Philippines (ranecaz@gmail.com)

Received: 2 January $2022 \quad$ Revised: 9 January $2022 \quad$ Accepted: 11 January 2022 Available Online: 11 January $2022 \quad$ DOI: $10.5861 /$ ijrse.2022.102

\section{Abstract}

Multi-grade teaching has played a vital role in molding learners especially in areas lack classrooms, teachers, and other learning resources. Given its vital role, researches have been conducted exploring the pedagogical knowledge, skills, and challenges in multi-grade teaching. However, more investigations are needed to document the lived experiences and teaching mechanisms of multi-grade teachers. In such lights, this phenomenological study was undertaken to describe the lived experiences of the teachers and their teaching mechanisms in multi-grade teaching. Through interviews with eight (8) with the aid of an aide-mèmoire, the study produced extended texts as a result of transcribing the interview recordings. These extended texts were subjected to cool and warm analyses which revealed that the participants' views on multi-grade teaching as challenging, fulfilling, love, and learning. In addition, the study surfaced the teaching mechanism of the participants which were dubbed as BADANGAM: Beginning with the Learners in Mind, Activating Interests through Varied Activities, Designing with the Learners in Mind, Adhering to Principles, Netting Learning through Varied Activities, Going Multi-Modal, Asking Questions, and Making Use of Varied Assessment. With these mechanisms, the BADANGAM Model in multi-grade teaching was formulated. Finally, the study recommends the provision of mitigation and intervention program and assistance to multi-grade teachers that shall help them outwit the challenges they face, the provision of reinforcing and additional trainings and seminars on teaching mechanisms in multi-grade teaching, the use of the BADANGAM model in multi-grade teaching, and the conduct of studies to test the effectiveness of the developed model.

Keywords: indigenized teaching, multi-grade teaching model, multi-grade instruction, phenomenology, qualitative research 


\section{BADANGAM: An indigenized multi-grade teaching model}

\section{Introduction}

In the education sector, multi-grade teaching is a scenario that reveals various realities concerning learning and teaching. It has been used in many countries around the globe, especially in rural areas of developing countries to make access for children to an in-depth primary education. Some attribute it to the geographical oddities, the social economic peculiarities, and the lack of adequate school infrastructure and personnel. Lucidly, it is commonly implemented in remote areas due to the shared circumstances of teacher shortage and relatively small numbers of students (Triwiyanto, 2017).

In addition, multi-grade teaching is a practice in which learners from different age, skill, and class level continue their education and training together in the same class and are taught by one teacher because of various reasons such as lack of teacher, lack of school, and low number of student (Ilter, 2015). It is one strategy to promote all children's access to education especially in the remote or rural areas. Due to this, it was executed many years ago in numerous countries around the world to achieve the goals of the education for all (Thephavongsa, 2018). Likewise, the UNESCO (2015) stated that it is an important way to help nation reach their internationally mandated education for all as a result multi-grade has been established worldwide. However, it is necessary to support multi-grade teachers in providing quality education for students.

Clearly, multi-grade teaching means to teach learners of different grades, ages and abilities in the same group. It is different from mono-grade teaching in which students within the same grades are seemed to be more similar in term of age and ability (Haq et al., 2017). Apparently, a class that contains learners of a single grade level and mixed abilities differentiate a mono-grade teaching.

Furthermore, Belleza and Feliciano (2018) articulated that the multi-grade program in Philippine plays a significant role in improving the quality of educational services and learning outcomes of learners specifically in remote and underserved rural communities of the country. Accordingly, it has been proven that multi-grade classes when given appropriate interventions, and their teachers provided with materials and appropriate training on affective approaches, can perform in accordance to standards. This highlighted the fact need to invest in recalibrating and upgrading the multi-grade education of the Philippines. After all, multi-grade schools have been established worldwide, and it is imperative to support teachers so they can provide a quality education to their learners (Taole \& Cornish, 2017).

Unfortunately, Joubert and Jordaan (2010) underscored that teacher training programs and curriculum support programs have not been developed to support multi-grade teachers. Accordingly, most rural children adopt the disposition of their families and communities, who in most cases are unschooled and have very poor literacy skills. In fact, Downey et al. (2008) noted that students at rural schools are more likely to be poor and to rank in the bottom quintile for learning.

Meanwhile, challenges on multi-grade teaching were revealed (Naparan \& Castañeda, 2021; Taole \& Cornish, 2017; Sampson \& Condy, 2016; Blease \& Condy, 2015). These include teaching learners who are of diverse backgrounds and grade level. Also, teachers are often than not required to double time in terms of lesson preparation and delivery. Likewise, the process of teaching different grade levels in one classroom is an exhausting task. Nonetheless, researchers revealed intrinsic and extrinsic challenges that confront multi-grade teachers. Moreover, the challenges in multi-grade teaching are even aggravated by the existing scarcity of learning materials and other resources. In fact, the Department of Education (DepEd) data showed shortages that the agency is yet to meet such as 13,995 classrooms, 88,267 teachers; 235 million instructional and other learning materials; 2.2 million school seats for 2016 and 66,492 sets - each seat with 45 seats and 1 teacher's desk; and 44,538 computer packages (Umil, 2017). Likewise, Intal (2018) stated that buildings, facilities and 
supplies are lacking. In the past years, it is undeniable that DepEd continuously address the said problems, but it is still far from being totally solved. Schools in the country still face similar problems.

Meanwhile, the accessible and available literatures on multi-grade instruction explored, described, and revealed evidently the knowledge, skills, and challenges of multi-grade teachers. The reviewed literatures also revealed that need to investigate the lived experiences of multi-grade teachers and their mechanisms in teaching. In such lights, this study was conceptualized.

Enthused by the abovementioned discussions on multi-grade instruction, the researcher found it imperative to describe multi-grade teaching of Cervantes District in Cervantes, Ilocos Sur. It is to note that the said district has a long history of offering multi-grade education in far-flung areas. Through this study, it is hope that the first hand experiences of multi-grade teachers provide a deeper understanding and more eidetic portrait of the context of multi-grade education.

\subsection{Statement of the Problem}

This study aimed to provide a clearer picture of multi-grade teaching of Cervantes District in Cervantes, Ilocos Sur from the experiences and perspectives of multi-grade teachers. Specifically, it sought answers to the following:

$>\quad$ What are the lived experiences of multi-grade teachers in teaching multi-grade learners?

$>\quad$ What mechanisms do multi-grade teachers employ in terms of: designing lessons; developing teaching aids; delivering lessons; and assessing learners?

$>\quad$ What teaching model in multi-grade teaching can be formulated for Cervantes District?

\section{Methodology}

This qualitative study utilized phenomenology as its research design. The participants, whose consents were secured, were chosen using criterion sampling in which two criteria were set. First, the teachers have taught for at least two years and are still teaching in a multi-grade classroom in any of the public elementary school of Cervantes District in Cervantes, Ilocos Sur. Second, they are willing to be interviewed and to participate in the study. With these criteria 13 teachers were identified, but the interviews ended with eight (8) multi-grade teachers when saturation of data was reached. Upon saturation of data, the interview recordings were transcribed to arrive at extended texts which were subjected to spot checking for accuracy of data. The study also employed members checking procedures through follow interviews, checking of the interview transcripts by the participants, and presentation of results to the participants (Azarias et al., 2020). Finally, the extended texts were subjected to cool and warm analyses leading to the development of the output of the study.

\section{Discussion}

\subsection{Lived Experiences of Multi-Grade Teachers}

Findings in this paper described the sharing of the teachers, who were coded as $\mathrm{T}$ for anonymity, on their lived experiences as multi-grade teachers. The opulence and depth of the extended texts afforded the researcher to identify the essence of their lived experiences as multi-grade teachers. Though the experiences happened in different contexts, the commonalities and picture of multi-grade teaching were identified through the cool and warm analyses.

In answering the first problem of the study, the answers of the participants on questions covering their lived experiences were subjected to cool and warm analyses. In the analyses and interpretation of the extended texts, 
Velasco, R. A., Ramos, A. O., \& Azarias, R. A.

four themes emerged which were dubbed as the four M's: Multi-Grade Teaching as Challenging, Multi-Grade Teaching as Fulfilling, Multi-Grade Teaching as Love, and Multi-Grade Teaching as Learning.

Multi-Grade Teaching as Challenging. In the lights of the experiences of the participants, the first theme was formulated to highlight that teaching in a multi-grade context entails struggles. The challenges shared by the participants primarily focused on handling diversities in class, dealing with learners' behaviors, teaching learners simultaneously, and new teaching-learning environment. The sample verbalizations below support the claim.

As a multi-grade teacher, I can say that it is not easy, but you know after the hardships I feel fulfillment. It's not easy because you know, I have to teach learners in different levels. It's not the typical classroom which is one grade level only. Added to the challenge is the diversity of my learners especially that they are kids. You know how kids behave when you do not attend to them. They have different behaviors. Some are naughty and playful while others are cry babies, so I have to consider all these. (T1)

So you see, it is not that easy because I get to prepare lessons for two grade levels. I have to teach them simultaneously. I have to handle differences among my learners. It's very challenging, (T2)

Teaching multi-grade for the first time is not that easy because as a beginner in the field, I still didn't have enough knowledge on the strategies in handling multi-grade class. In my case, it felt like I was submerged in hot water with bagoong because I did not know where to begin. I felt different emotions at the very first day of my multi-grade life. (T4)

To be a multigrade teacher is like conquering a vast ocean with gradual, huge waves coming to you. Many challenges come to my way sometimes I am not prepared but I am willing to take risks. (T8)

The finding supports Erden (2020) who revealed that teachers teaching at multi-graded classrooms found multi-graded teaching difficult and challenging. Likewise, Naparan and Castaňeda (2021) discussed that teachers find it challenging to hone the skills of students coming from multiple grade levels, and they need to manage their time well for them to help better the learners of different year levels. Also, the finding of the study conforms to the study of Taole and Cornish (2017) which stated that teachers in multi-grade schools are confronted with significant challenges as they have to teach two or more age groups simultaneously and possibly more than one curriculum subject. Similarly, the finding supports Blease and Condy's (2015) discussion which stated that multi-grade teachers usually experience problems with students' skills, such as difficulty in writing and other academic problems. Despite the challenging nature of multi-grade teaching as the participants shared, their vigor and passion manifested while they described experiences during the interviews.

Finally, one can only assume the difficulties teachers and students experience while teaching and learning take place in multi-graded classrooms (Erden, 2020). Teachers, in the lights of the challenges they face, truly depend on their professionalism on teaching, their knowledge, which they define their knowledge as deep contextual, reflexive and adaptive, helping them to activate teaching and learning (Ramrathon \& Ngubane, 2013). Thus, training is needed to develop teachers' professional and personal competencies (Cadosales, 2017).

Multi-Grade Teaching as Fulfilling. The previous theme suggests negative vibe in multi-grade teaching. Interestingly, the participants lucidly shared more positive views on multi-grade teaching. One of these is the second theme which accentuates the fulfillment they feel as multi-grade teachers. The sense of fulfillment centered on seeing the transformation among their learners. As verbalized:

With the difficulties of teaching them, I find happiness and fulfillment because at the end of the day you see them learn to read, write, do math, sing, act, dance, and show good values. I see them transform everyday compared to their versions when I first met them. (T1)

30 Consortia Academia Publishing (A partner of Network of Professional Researchers and Educators) 
BADANGAM: An indigenized multi-grade teaching model

... but you know it's always fulfilling because I get to see the growth in my learners. I get to see them being able to read, write, sing, do math which they don't know before they become my pupils. That is the reward of all the challenges and problems of being a multi-grade teacher. (T2)

It is fulfilling when you see your learners learn how to read, write, solve basic mathematics, dance sing, and smile despite the academic stress. (T3)

Teaching multi-grade is also rewarding when your pupils and parents appreciate your effort and patience in teaching kids. (T5)

It is not easy, but you know I am happy. I am always fulfilled especially when I see the transformations of my learners from a blank slate to people who can read, write, have values, can communicate, or do basic math. It is fulfilling because I am learning many things not only from my seminars but more on my teaching. (T6)

Clearly, the participants related their fulfillment or satisfaction as multi-grade teachers to the development or learning that their learners show in the course of their exposure to multi-grade instruction. This supports Falken' (2021) who underscored the fulfilling part is when a learner gains new insight and then becomes excited. Similarly, the fulfilling part of being a teacher is when teachers can influence the new generations and mold them for a better future, in a major way setting a positive example (Falken, 2021; Zechariah, 2002). Consequently, Braithwaite et al. (2017) articulated that only a few teachers that being a teacher is something they regret doing the common reason is that they find fulfillment in influencing students and helping them in shaping the future.

Notably, the positive outlook of the participants on multi-grade teaching is indicative of the satisfaction they have despite the fact that it is challenging. Teachers who feel good about themselves and their profession have a positive attitude on the job, which, of course, also positively affects their students (Dennis, 2012). Satisfied teachers were also more likely to be involved in activities at the school site and participate in school activities (Weiqi, 2007). Also, satisfied teachers offer higher instructional quality and better learning support for their students (Kunter et al., 2013). The fulfillment shared by the participants suggests also their strong commitment to the job as multi-grade teachers because they make that their learners learn something from them despite the challenging nature of multi-grade teaching. In fact, Blömeke et al. (2017) and Klassen and Chiu (2011) also shared that teacher who demonstrates stronger job commitment and are less prone to leave the profession.

Multi-Grade Teaching as Love. In the lights of the challenges that participants met, they still view multi-grade teaching as love. According to them, the love they have for teaching in multi-grade setting keeps them from leaving their posts as multi-grade teachers. Their love also allows them to withstand the tests of being multi-grade teachers. In fact, the best thing about teachers is that they do love teaching despite all the challenges and hardships they face regularly (Falken, 2021). This characterizes the theme. To support the claim, the statements below are excerpted from the extended texts.

The experiences of being a multi-grade teacher is love because if I don't love it, I will never succeed or grow as a teacher. The fact that I don't only attend to one type of learner every day and I am still here show that I love what I am doing. When you don't love it, you can't survive. When you put your heart into it, you will never be questioned. I may not be the best, but I am surely loving being a multi-grade teacher and that is beyond questioning. In fact, when you become a multi-grade teacher, you learn a lot that cannot be learned from the four corners of the classrooms. (T1)

For me, experiencing those experiences is a product of my love and passion for teaching. I cannot endure the hardships or difficulties of the mission if I don't love what I am doing. As a teacher, you have to love all aspects of teaching be it be stress, problems, happiness, complaints 
Velasco, R. A., Ramos, A. O., \& Azarias, R. A.

and among others because I took oath to be a teacher.

(T2)

The experiences of being a multi-grade teacher is I can say that it is a test of patience, love for teaching, and flexibility. It's a test of patience because I am teaching children and you know their nature. They are naughty and playful. It's a test of love for teaching because it brings me to a point when I seem to falter. It's just like I want to give up because imagine I am teaching two levels sometime three if kinder is included. But the more I teach, the more I love teaching. (T3)

Apparently, love for teaching is a vital ingredient in their survival and success as multi-grade teachers. Hough (2018) highlighted that one can teach basic skills without love, but to truly make a difference in a student's life, there needs to be love. Accordingly, love sees teaching as an art where we explore different ways of connecting to subject matter and to students, and it brings patience and understanding, which are so important in teaching

Evidently, the verbalizations of the participants suggest their strong passion for teaching that is also a vital component of their positive attitude towards multi-grade teaching amidst the challenges that it offers. Serin (2017) articulated that passionate teachers are committed to creating an effective learning environment and increase the learning potential of students. Accordingly, passion contributes to creativity, thus passionate teachers have more thinking skills and can easily produce new ideas.

Multi-Grade Teaching as Learning. Through the verbalizations and answers of the participants, multi-grade teaching is viewed as learning. Being exposed in multi-grade setting allows the participants to learn skills and knowledge they need as teachers. Also, they also enhanced their knowledge and skills as they teach in multi-grade setting. These picture the theme. The verbalizations below justify the formulation of the theme.

You know, being a multi-grade teacher gives you a lot of things, both pedagogic and life lessons. I learn things I never knew before... In short, I learn how to become a teacher and what teaching is all about because you know the best teachers I think are those that are able to experience how to become superteacher in multi-grade classroom because patience, skills, talents, and creativity are being tested every day. (T2)

Knowledge I have gained from teaching multi-grade learners or from multi-grade classroom setting are the following: a. learners' diversity must be determined prior to the development of instructional resources; $b$. knowledge in instructional material development; $c$. knowledge in ICT or use of modern technology; $d$. using theory in practicelapplying theories to teaching; $e$. patience is the first to keep in mind in teaching multi-grade (T3)

I've become better in managing my time and designing lessons... time management and being flexible in giving activities (T5)

I learned to apply all theories and teachings from my college, masters and seminars that I had. I learned new technology to use in teaching. I learned to manage my time. I have improved my organizing skills. I become good in communicating using the mother tongue and English. I improved my classroom management skills and many more. I have become a teacher who understands my learners and technology that they are in. (T6)

The abovementioned statements revealed the pedagogical knowledge and skills of the multi-grade teachers as a result of their education and experiences as multi-grade teachers. Mentioning those knowledge and skills means that the participants find this knowledge or skills imperative in their lives as multi-grade teachers. These refer to the specialized body of knowledge concerned with creating effective teaching and learning environments for each and every student (Schleicher, 2016). Knowledge of how to structure learning objectives, how to plan a lesson, how to evaluate a lesson, knowledge of effective use of allocated time and strategies for differentiated instruction, and knowledge of how to design tasks for formative assessment are examples of these pedagogical

32 Consortia Academia Publishing (A partner of Network of Professional Researchers and Educators) 
knowledge.

Notably, the sharing of the participants accentuates the reality that teaching is a perpetual pursuit. Teachers learn more as they teach. In fact, Silver (2018) forwarded that teachers need to be lifelong learners and take advantage of the many professional development opportunities that are available for them to expand their repertoire of teaching strategies. Accordingly, excellent teachers regularly adjust and adapt their approach as they reflect on their experiences and improve upon them throughout their careers. Also, Braithwaite et al. (2017) stated that aside from teaching in subject area of specialization, teachers learn many things like being a coach, running a school club, and being guidance counselors.

3.2 Multi-Grade Teachers' Mechanisms in Designing Lessons, Developing Teaching Aids, Delivering Lessons, and Assessing Learners

As multi-grade teachers, the participants shared their mechanisms in terms of designing lessons, developing teaching aids, delivering lessons, and assessing learners. The cool and warm analyses of the extended texts as products of the sharing of the participants yielded eight themes which were tagged as BADANGAM. In designing lessons, the teachers employ two mechanisms: Beginning with the Learners in Mind and Activating Interests through Varied Activities. In developing teaching aids, they resort to two mechanisms: Designing with the Learners in Mind and Adhering to Principles. In delivering the lessons to their learners, they utilize three mechanisms: Netting Learning through Varied Activities, Going Multi-Modal, and Asking Questions. In assessing learners, the participants articulated the use of varied assessments; thus, the theme Making Use of Varied Assessment emerged.

Beginning with Learners in Mind. In the teaching and learning process in multi-grade setting, learners are always put in the fore front of the pedagogical wheel. This describes the first theme for the mechanism of participants in designing their lessons. To support the claim, the verbalizations of the participants are excerpted below.

As I stated, I consider my learners' backgrounds so that all the activities can fit their learning styles or preferences. I have to vary activities so that they will not be bored. (T1)

As I said, I always put my learners first. Then everything will go smoothly. I need to know them. I need to see how they learn. I need to know their styles, their family backgrounds and others so that I know what activities to give and what teaching materials to use. (T2)

I have to make sure that my objectives are attainable and suited to my pupil's level, interest and the competencies that they must acquire. The class size, learners' background, learner's diversity level of my learners should be considered.(T3)

I consider their interest because sometimes I cannot proceed to the lesson without considering it. I also consider the time, their level and the availability of materials to be used in teaching. (T4)

I consider my learner's differences; their level, background, time, interest, religion. (T5)

As they always say, put your learners first. That is what I do. I consider my learners. I need to know their backgrounds. (T6)

their background, level, time and interest ... they are the main concern in teaching learning process (T7)

The verbalizations of the participants accentuate that profiling and understanding learner's background is the key to a well-design lessons. Walton-Fisette (2010) articulated that getting to know and understanding students should be the primary purpose of teaching. This means that learners are always put in the center of the 
Velasco, R. A., Ramos, A. O., \& Azarias, R. A.

educational realms. Putting them as the center of lesson designing helps teachers determine the things that should be incorporated in the designing and delivery of instruction. In this way, better aligned instruction can also help to achieve equity goals by ensuring that no child is left behind (Rodriguez-Segura et al., 2020).After all, Erden (2020) stressed that each student's diversity, complexity, gender, age, family background, socioeconomic background, language level, abilities, skills and special education should be well known by the multi-graded classroom teachers to produce better learning because a student may learn through peers, self-directed, cooperatively and/or various learning styles.

Activating Interests through Varied Activities. As teachers design their lessons for their multi-grade learners, they design and use various activities to make sure that engagement and participation in their classrooms pervade. Through this mechanism, the interests of their learners are secured. As verbalized:

Usually games and drills because they are kids they are not adults that they enjoy lecture pure discussion. Remember children get bored easily. (T1)

I have to engage them. I have to let them recite or participate. I give games and drills. I let them play as they learn. I don't confine them inside my class... I give games, drills, quizzes, performance tasks, and I let them recite through question and answer. (T2)

Playing games (bingo games, word hunting, word puzzle, building blocks, snake and ladder), drawing, painting, singing, dancing, reading with a partner, role playing (kankana-ey), sharing (on Mondays or after holidays), bring me, storytelling. (T3)

Drawing and dancing make them express themselves in the most productive way. (T4)

My learners love to dance, sing, draw, and spell words that is why we do those activities every day. (T5)

Usually let them watch a short film. It's just like reading a story to them that I frequently ask questions before proceeding to the next event. Another thing is solving basic math problems on the board. Whoever answers first their team gets a point. Since they are very active, they like to sing, dance, jump and other physical activities. (T8)

Similarly, Renninger and Bachrach (2015) discussed that triggering interest can be achieved through activities and the learners' characteristics. The participants viewed the use of varied activities as imperative component of multi-grade lesson designing. Their verbalizations imply that using varied or differentiated methods and strategies is to facilitate the learning of all students. In fact, Burke (2021) mentioned that this is finding ways to make lessons appeal to students with different interests, experiences, abilities, and learning styles.

Designing with Learners in Mind. Like the mechanism of participants in designing their lessons, they also share that the diversity among their learners serves as the basis in designing their teaching aids. The backgrounds of their learners guide them in determining the appropriate teaching aids to be used in their classes. The statements below justify.

I think the basic rules is to consider my learners' background, learners' level, learners' learning style. (T1)

In designing the teaching aids, I profile my learners. I observe how they learn. (T6)

I always consider their level which includes their age, IQ and interest, and environment. (T7)

Learner's level and cultural background, ((when the teacher was asked about things she considers in developing teaching aids)) (T8)

34 Consortia Academia Publishing (A partner of Network of Professional Researchers and Educators) 
The statements of the participants corroborate Royal Charters' (2017) discussion which said that individual needs and learning styles of learners are two of the main factors that should be taken into consideration when preparing teaching and learning materials. Also, Schultz (2015) noted that teachers who know how their kids learn can guide them and lead them to grow in their learning. The finding means that understanding the diversities among learners is a vital ingredient of well-designed teaching aids. Note that teaching aids cannot be successful if they do not conform to the diversities of learners. The time and effort of teachers in preparing them become futile if those aids will not serve their purposes. Apparently, the teaching material should meet the needs and wants of the learners (Tomlinson, 2010).

Adhering to Principles. In designing teaching aids, the participants articulated the need to consider the appropriateness, appeal, readability, and usefulness of the teaching aids that they will use. These criteria become their guide in developing their teaching aids in multi-grade setting. The statements below justify the claim.

I need to know their styles for me to make appropriate, readable, appealing, and useful teaching aids. (T2)

I get to design appropriate and readable teaching materials. (T6)

I have to consider also the readability and appeal of the teaching aids. When my learners see something appealing they ask a lot like ania data ma'am? (T1)

I need to know their styles for me to make appropriate, readable, appealing, and useful teaching aids. (T2)

appropriateness of teaching aids, readability, appeal of the teaching aids ((When asked about the factors or things that she considers first in designing teaching aids)). (T3)

colorful, attractive, useful ((When asked about the factors or things that she considers first in designing teaching aids)). (T4)

Teaching aids must be attractive, safe and useful ((When asked about the factors or things that she considers first in designing teaching aids)). (T5)

appropriateness, availability of resources, learner's level and cultural background, and attractiveness ((When asked about the factors or things that she considers first in designing teaching aids)) (T8)

The sharing of the participants implies that following principles or criteria of teaching aid preparation and construction leads to a well-design material. Tomlinson (2010) also revealed that teachers should consider principles [like those mentioned by the participants] when developing classroom materials. Erden (2020) pointed that the innovation level and creativity level must become known in the teaching-learning environment to improve and make such actions sustainable in multi-grade teaching.

Netting Learning through Varied Activities. In the multi-grade pedagogy, the ability of teachers to maximize learning as they deliver their lessons is vital. They need to design various activities to sustain and catch their learners' learning interests and attention as vital requisites of successful multi-grade instruction. This depicts the first theme on mechanisms in delivering lessons. As verbalized:

Basically, I give activities that allow them to apply what they learned like the ABAKADA, I have to let them read.

Same answer, I give activities that allow them to use our lessons. I give games. I give drills. (T1)

Let them apply the lesson. Give quizzes and performances, but make sure to vary them and make sure to let them enjoy... I give games. I let them recite every time I ask questions. (T2) 
Velasco, R. A., Ramos, A. O., \& Azarias, R. A.

I ask questions, let them perform tasks that require them apply the lesson. (T3)

I also let them draw their feelings about the story they have read or listen to. (T5)

Application of the lesson is always the key. So I have to give drills and performance test so that I will know if they learn something from me. (T6)

I give them enhancement activities or sometimes I let the smart ones tutor the slow learners... involving them in discussions and activities like playing fun games (T8)

From the abovementioned statements, the participants revealed that activities requiring their learners to apply their lessons are essential in delivering the lessons. This is one way of relating the lessons to the learners' lives and experiences. Theobald (2006) revealed that learners who understand the relevance for learning a particular concept, and what that learning implies for their everyday living, will generate interest. In fact, Thoonen et al. (2011) revealed that that connecting to the personal world (relevance) of students had a positive outcome on students' motivation. When teachers connect learning to the personal world of their learners by making learning tasks more relevant through relating instructions to students' experiences (Ferlazzo, 2015; Thoonen et al., 2011), they will see the links between what they do in class and how meaningful it is to their lives (Martin et al., 2002).

Going Multi-Modal. As multi-grade teachers, the participants shared that in explaining their lessons they use variety of teaching aids. In so doing, the theme is operationally referred to as the ability of teachers to use variety of teaching aids in order to deliver their lessons. In so doing, they are not confined into one modality or type of teaching aids. The use of variety of multi-media materials is evident. The participants verbalized:

I use the usual flashcards, bulletins, manila paper, reading materials. Now, I use laptops and projectors because we have electricity now, but I have to back up those with printed because electricity is unstable in our place. (T1)

From that I can now make my flashcards, powerpoint, diagrams etc. the usual materials in elementary class because we have programs for such. I think you know that we have to make reading corner etc. the task of being an elementary teacher. (T2)

Laptop, projector, charts, pictures, flash cards, realia, reading materials, speaker ((When asked about the teaching aids being used in the class)).

I use attractive materials in teaching like pictures and I also tell funny stories. (T5)

Pictures, flash cards, reading materials, realia ((When asked about the teaching aids being used in the class)). (T5)

The statements of the participants reveal the vital role of using teaching aids in the success of delivery of instruction. In fact, Olayinka (2016) point out that they give room for acquisition of skills and knowledge and development of self- confidence and self- actualization. Accordingly, they enable both the teachers and students to participate actively and effectively in lesson sessions.

Finally, the use of instructional materials in the classroom has the potential to help the teacher explain new concepts clearly, resulting in better student understanding of the concepts being taught (Tuimur \& Chemwei, 2015). As such, teachers are compelled to facilitate learning through the use of varied teaching materials that shall help them achieve their objectives.

Asking Questions. Questioning is vital aspect in the teaching and learning process. Through this, teachers get ideas that aid them in teaching their learners. The theme emerged as the participants shared that they ask questions whenever they discuss their lessons. This is one way for them to engage their students into discussion

36 Consortia Academia Publishing (A partner of Network of Professional Researchers and Educators) 
and participation. They articulated:

I ask questions to random learners. I let them recite. I let them enjoy the games. I give rewards or even let them compete with groups for a fun game. (T1)

Ask questions. Give quizzes and performances, but make sure to vary them and make sure to let them enjoy. (T2)

Also, I give activities, games, and ask questions, let them recite to trigger their interest.

Calling their attention. I let them feel that they are important so they should learn by participating... I catch their attention by giving fun games. (T4)

I always ask divergent questions to develop their critical thinking skills even though they are still young. (T5)

I give graded recitation. I ask questions. (T6)

Clearly, the verbalizations of the participants conform to Yang's (2006) finding stating that the teacher's questions can be considered as the most powerful device to lead, extend and control communication in the classroom. Although questioning has long been thought of as an important aspect of education, more recent research studies indicate it has been brought to the forefront as a critical component of effective teaching (Hannel, 2009). Consequently, it increases curiosity, piques interest, and causes increased motivation when teachers use questioning effectively (Caram \& Davis, 2005).

Notably, the statements of the participants revealed that when teachers create a classroom culture that requires students' continuous participation through answering complex, high- level questions at their cognitive level, it leaves them no choice but to be engaged (Hannel, 2009; Walsh \& Sattes, 2005). Apparently, the use of a variety of techniques for questioning such as planning for and scaffolding questions stimulates student achievement and growth in the classroom (Phillips, 2013). Hence, good questioning techniques need to be modeled in order for students to become skilled in both thinking and questioning; because questioning leads to problem solving, quality questions will lead to quality decisions (Nappi, 2017).

Making Use of Varied Assessment. In any aspect of educational process, assessment plays a vital role in determining the achievement of learning objectives and the success of instruction. In the case of multi-grade teachers, they make sure that they assess their learners using variety of assessment. Accordingly, they make use of variety of assessments to make learning more interesting. The verbalizations below justify the claim.

I give quizzes. I let them recite. I ask questions. I let them apply the lesson. I give time for them to practice what they have learned. Paper pencil tests and performance test are also given to see if they learn something. These allow me to see if they really learn something and to make learning more interesting. (T1)

For more interesting learning, I let them apply the lesson. Like I give projects. I let them solve problems. I engage them. I ask questions. I let them perform. I let them apply the lessons in real life situation. Drills and games are the best.

I give activities, games, and ask questions, let them recite, let them do activities that require them to apply what they learned... short quiz, short activities, games, and other task that require them to apply their lesson in order to arouse their interest. These help me determine if they learned the lesson. (T3)

I give seatwork and performance task

I give short quizzes and games where they can apply what they have learned. This helps me 
Velasco, R. A., Ramos, A. O., \& Azarias, R. A.

determine if they understand the lesson. These make my class interesting.

I give quizzes, performance tasks, and fun games... These activities let me know if they understand the lesson or if the methods I employed are effective, and allow me to make my class assessment interesting. (T5)

I test my learners by giving quizzes, performance test, drills, and others. I let them apply all the things we discussed. The result of their assessments tells if my objectives are met. (T6)

The statements of the participants support Erden (2020) who revealed that a multi-graded teacher needs to design or produce assessment strategies to meet the individual requirements of the students because each student has got different backgrounds, learning styles and needs. Notably, assessment should be varied to determine if set objectives or goals are met. In fact, the assessment techniques used by the teachers, the frequency of the assessment activities, the feedback given to the students, and the presentation of the assessment results constitute an assessment environment for every classroom (Buldur \& Doğan, 2014).

Finally, Miller et al. (2009) pointed out that assessment is very important for effective instruction because it is a process of determining what the students know, what they are capable of doing and what they are interested in. Consequently, it has a strong effect on students' various affective and cognitive characteristics, such as their learning approaches (Biggs, 2003; Hamdorf \& Hall, 2001), and their academic achievement and attitudes (Taş et al., 2013). As such, assessments should meet and address their learning styles, needs and diversities.

\subsection{Teaching Model in Multi-Grade Teaching}

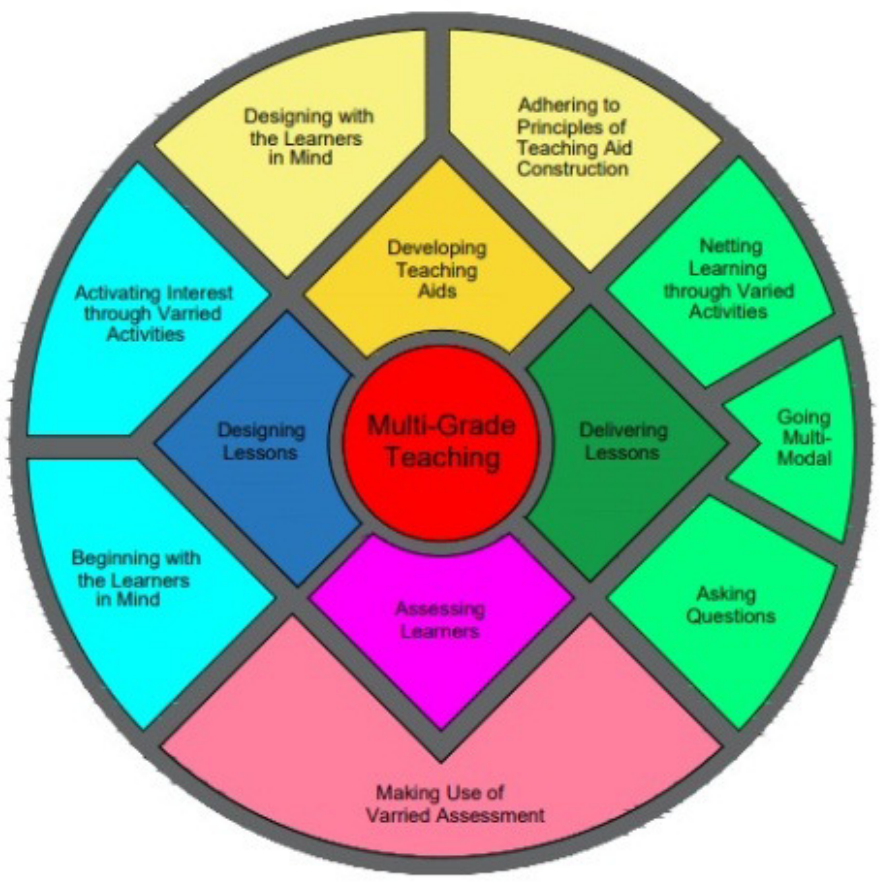

Figure 2. BADANGAM: Teaching Model in Multi-Grade Teaching

In this study, four aspects of multi-grade teaching are explored: designing lessons, developing teaching aids, delivering lessons, and assessing learners. In these four aspects of multi-grade teaching, the mechanisms of teacher were identified as they shared their experiences as multi-grade teachers. The rich sharing of the participants led to the formulation of the teaching model in multi-grade teaching in the context of Cervantes District in Cervantes, Ilocos Sur which is dubbed as BADANGAM Model. The term BADANGAM is a Kankanaey word which means to help. This is also a word variation for Binnadang which is a Cervantesian 
Kankanaey word for Bayanihan or pagtutulongan. With that being said, the BADANGAM if use in a sentence would mean that one should/shall/will help people who need help. As such, the BADANGAM Model suggests that multi-grade teachers serve as the concerned individuals that shall help the learners maximize their potentials and learning in multi-grade instruction. In doing this noble cause, the teachers use the mechanisms, as exemplified in the previous discussion, which are themed as Beginning with the Learners in Mind, Activating Interests through Varied Activities, Designing with the Learners in Mind, Adhering to Principles, Netting Learning through Varied Activities, Going Multi-Modal, Asking Questions, and Making Use of Varied Assessment (Fig. 2).

\section{Conclusion}

Cervantes District in Cervantes, Ilocos Sur has long been offering multi-grade instruction in the different barangays of the municipality. With this long history of the district in delivering multi-grade instruction, dearth of studies pervades. This dearth alongside the interesting nature of multi-grade instruction served as the one of the compelling force that led to the conceptualization of this study. As such, this study described multi-grade teaching as it is lived and experiences by multi-grade teachers of Cervantes District.

The cool and warm analyses the extended texts revealed the views of multi-grade teachers on multi-grade teaching as they share their lived experiences. The participants acknowledged the challenging nature of multi-grade teaching. Despite the challenges of multi-grade teaching, the participants still manifested positive views on multi-grade instruction. In fact, they articulated that multi-grade teaching is fulfilment, love, and learning. Evidently, their positive views as a result of their experiences circumvent the challenges they face. Clearly, they demonstrate flexibility, passion, and dedication as they dispense their roles, duties, and responsibilities as multi-grade teachers.

In addition, their mechanisms along designing lessons, designing teaching aids, delivering lessons, and assessing learners emerged which led to the formulation of the BADANGAM Model. The verbalizations of the participants clearly suggest placing the learners at the center of multi-grade instruction. Notably, diversifying learning activities, using proper and appropriate teachings aids, asking questions, and varying assessment are imperative in the success of multi-grade instruction. These indicate that multi-grade teachers eclectically make use of the theoretical and skills knowledge they have in accordance to their pedagogical contexts or the diversity of their learners.

Finally, the BADANGAM Model which resulted from the verbalizations of the participants highlights the vital role of teachers in multi-grade instruction, to help the learners. The mechanisms that the participants shared indicate that teachers remain steadfast with the changes and demands in education sector. The emergence of contextualized teaching model in multi-grade instruction accentuate that real scenarios of teaching world transcend theoretical understanding of teaching and learning. Hence, the provision of quality, relevant, and excellent education to multi-grade learners relies on the contextualized pedagogical skills and knowledge of the teachers.

\subsection{Recommendations}

In the lights of the findings and conclusions of the study, the following recommendations are forwarded:

$>\quad$ As a way of circumventing the challenges of multi-grade teaching, the Department of Education and its officials may match and reinforce the positive views of multi-grade teachers through providing relevant intervention or mitigation programs and assistance to them.

$>\quad$ School officials may formulate training programs that shall reinforce identified mechanisms in multi-grade instruction and that shall provide additional knowledge on multi-grade instruction which the teacher could use in furthering their teaching mechanisms. 
Velasco, R. A., Ramos, A. O., \& Azarias, R. A.

$>$ The BADANGAM Model in multi-grade instruction may be pilot tested or used for improvement.

$>\quad$ Further studies should be conducted to test the effectiveness of the developed model. Relevance and applicability of the trainings and education provided to multi-grade teachers should also be explored for policy and training formulation.

\section{References}

Azarias, A. R., Ballocanag, R., Ramos, A. O. ... \& Holmes, M. V. M. (2020). Freewill in pedagogy: Phenomenologizingthe lived experiences of seasoned teachers. International Academic Journal of Education \& Literature, 1(7), 329-334.

Belleza, J., \& Feliciano, E. (2018). Multi-grade intermediate mathematics teaching schemes: The case of education in District of Tublay, Benguet. Mountain Journal of Science and Interdisciplinary Research, 78(2), 115-136.

Biggs, J. B. (2003). Teaching for Quality Learning at University, $2^{\text {nd }}$ ed. Buckingham: Society for Research into Higher Education and Open University Press.

Blease, B. \& Condy, J. (2015). Teaching of writing in two rural multigrade classes in the Western Cape. Reading \& Writing 6(1).

Blömeke, S., Houang, R., Hsieh, F. J., \& Wang, T. Y. (2017). Effects of job motives, teacher knowledge and school context on beginning teachers' commitment to stay in the profession: A longitudinal study in Germany, Taiwan and the United States. In G. K. LeTendre\& M. Akiba (Eds.), International handbook of teacher quality and policy (pp. 374-387). London: Routledge.

Braithwaite, P., Moore, S. Saba, D., Dieringer, L., De Bruycker, M., Smith, P. Mysak, J. \& Harding, L. (2017). Teachers of Tomorrow: Why Become a Teacher? Retrieved on September 2, 2021 from https://www.teachersoftomorrow.org/blog/insights/should-i-be-a-teacher

Buldur, S., \&Doğan, A. (2014). Adaptation of the students' perceptions of the science and technology course classroom assessment environment scale into Turkish. Education and Science, 39(176), 199-211.

Burke, J. (2021). 15 Ways to Vary Instruction. Retrieved on September 2, 2021 fromhttps://www.scholastic.com/teachers/articles/teaching-content/fifteen-ways-vary-instruction/

Cadosales, M. N. (2017). Teaching efficacy of elementary students teachers. Journal of Research in Administrative Sciences, 6(1), 7-12.

Caram, C. A., \& Davis, P. B. (2005). Inviting student engagement with questioning. Kappa Delta Pi Record, 42(1), 18-23.

Dennis, M. (2012). A study of how teachers show love in the classroom (Doctor of Education Dissertation). Retrieved on September 2, 2021 http://digitalcommons.georgefox.edu/edd/13

Downey. D. B., Von Hippel, P. T. \& Hughes, M. (2008). Are "failing" schools really failing? Using seasonal comparison to evaluate school effectiveness. Sociology of Education, 81(3), 242-270.

Erden, H. (2020). Teaching and learning in multi-graded classrooms: Is it sustainable? International Journal of Curriculum and Instruction, 12, 359-378.

Falken, D. (2021). Why teaching is so fulfilling. Retrieved on September 2, 2021 from https://www.linkedin.com/pulse/why-teaching-so-fulfilling-dena-falken

Ferlazzo, L. (2015). Strategies for helping students motivate themselves. Retrieved October 6, 2021, from http://www.edutopia.org/blog/strategies-helping-studentsmotivate-themselves-larry-ferlazzo

Hamdorf, J., \& Hall, J. C. (2001). The development of undergraduate curricula in surgery: III. Assessment. The Australian \& New Zealand Journal of Surgery, 71, 178-183.

Hannel, I. (2009). Insufficient questioning, Phi Delta Kappan, 91(3), 65-69.

Haq, G. N., Farooq, R. A., \&Tabassum R. (2017). Comparison of Multi-grade Teaching with Mono-Grade teaching at Primary Level. Journal of Applied Environment and Biological Sciences.

Hough, 1. (2018). What's Love Got to Do With It? John Miller's new book looks at the role love and compassion play in education. Harvard Graduate School of Education. 
BADANGAM: An indigenized multi-grade teaching model

Ilter, İ. (2015). Sınıf Öğretmeni Adaylarının Birleştirilmiş Sınıf Kavramına İlişkin Metaforları. İlköğretim Online, 14(4), 1450-1468.

Intal, A. D. (2018). Status of K to 12 in education system of the Philippines. Retrieved on January 19, 2020 from https://www.pressreader.com/

Joubert, J., \& Jordaan, V. A. (2010). Pedagogy of multigrade. Unpublished paper presented at the Southern African Conference for Multigrade Education, Paarl, South Africa, 22 to 24 March.

Klassen, R. M., \& Chiu, M. M. (2011). The occupational commitment and intention to quit of practicing and pre-service teachers: Influence of self-efficacy, job stress, and teaching context. Contemporary Educational Psychology, 36(2), 114-129.

Kunter, M., Klusmann, U., Baumert, J., Richter, D., Voss, T., \& Hachfeld, A. (2013). Professional competence of teachers: Effects on instructional quality and student development. Journal of Educational Psychology, $105(3), 805$.

Martin, J. J., Kulinna, P. H., \&Cothran, D. (2002). Motivating students through assessment. Journal of Physical Education, Recreation \& Dance, 73(8), 18-19. https://doi.org/10.1080/07303084

Miller, M., Linn, R., \& Gronlund, N. (2009). Measurement and Assessment in Teaching, $10^{\text {th }}$ ed. Upper Saddle River, NJ: Pearson.

Naparan, G. \& Alinsug, V. (2021). Classroom Strategies of multigrade teachers. Social Sciences and Humanities Open, 3(1), 1-6. https://doi.org/10.1016/j.ssaho.2021.100109

Naparan, G. B., \& Castañeda, I. L. P. (2021). Challenges and coping strategies of multi-grade teachers. International Journal of Theory and Application in Elementary and Secondary School Education, 3(1), 25-34.

Nappi, J. S. (2017). The importance of questioning in developing critical thinking skills. International Journal for Professional Educators, 84(1), 30-41.

Olayinka, A-R.B. (2016). Effects of instructional materials on secondary schools students' achievement in social studies in Ekiti State, Nigeria. World Journal of Education, 6(1), 32-29.

Phillips, E. (2013). A case study of questioning for reading comprehension during guided reading. Education, $41(1), 110$.

Ramrathon, L., \& Ngubane, T. I. (2013). Instructional leadership in multi-grade classrooms: What can mono-grade teachers learn from their resilience? education as change: Issue sup 1: School Instructional Leadership, 17(1), S93-S105. https://doi.org/10.1080/16823206.2014.865995

Renninger, K. A., \& Bachrach, J. E. (2015). Studying triggers for interest and engagement using observational methods. Educational Psychologist, 50(1), 1-12 https://doi.org/10.1080/00461520.2014.999920

Rodriguez-Segura, D., Campton, C., Crouch, L., \& Slade, T. (2020). Learning inequalities in developing countries: Evidence from early literacy levels and changes. International Journal of Educational Development.

Royal Charter. (2017). Factors to consider when selecting instructional materials. Retrieved on September 3 , 2021 fromhttps://www.open.edu/openlearncreate/mod/page/view.php?id=168511Sampson, C., \& Condy, J. (2016). One teacher's experiences of teaching reading in an urban multigrade foundation phase class. Perspectives in Education, 34(2), 83-96. https://doi.org/10.18820/2519593X/pie.v34i2.7

Sampson, C., \& Condy, J. (2016). One teacher's experiences of teaching reading in an urban multigrade foundation phase class. Perspectives in Education, 34(2), 83-96. https://doi.org/10.18820/2519593X/pie.v34i2.7

Schultz, M. (2015). The Importance of Getting to Know Your Students. Retrieved on September 3, 2021 from https://www.bamradionetwork.com/the-importance-of-getting-to-know-your-students/

Serin, H. (2017). The role of passion in learning and teaching. International Journal of Social Sciences and Educational Studies, 4(1), 60-64.

Silver, F. (2018). What skills knowledge \& experiences are needed to become a teacher? Retrieved on September 2, 2021 from https://work.chron.com/skills-knowledge-experiences-needed-become-teacher-14030.html

Taole, M. J., \& Cornish, L. (2017). Identifying the professional knowledge base for multi-grade teaching. The Online Journal of New Horizons in Education, 7(4).

Taş, E., Karakaya, M., Çetinkaya, Ç., \&Apaydin, Z. (2013). An investigation on web designed alternative 
Velasco, R. A., Ramos, A. O., \& Azarias, R. A.

measurement and assessment approach. Education and Science, 38(167), 196-210.

Theobald, M. A. (2006). Increasing student motivation: Strategies for middle and high school teachers.

Thousand Oaks, CA: Corwin Press.

Thephavongsa, S. (2018). Enhancing the teaching skills of the multi-grade teachers through lesson study. International Journal of Learning, Teaching and Educational Research, 17(4), 71-87.

Thoonen, E. E. J., Sleegers, P. J. C., Peetsma, T. T. D., \& Oort, F. J. (2011). Can teachers motivate students to learn? Educational Studies, 37(3), 345-360. https://doi.org/10.1080/03055698.2010.507008

Tomlinson, B. (2010). Principles and procedures of materials development. In N. Harwood (Ed.) Materials in ELT: Theory and Practice. Cambridge: Cambridge University Press.

Triwiyanto, T. (2017). Multigrade teaching: a solution for teacher shortage and educational quality improvement in Indonesia. Journal of Business and Economics, 8(10), 867-875.

Tuimur, H. N., \& Chemwei, B. (2015). Availability and use of instructional materials in the teaching of conflict and conflict resolution in primary schools in Nandi North District, Kenya. International Journal of Education and Practice, 3(6), 224-234.

Umil, A.M. (2017). New school year, same old problems: K to 12, shortages in classrooms, teachers. Retrieved on January 19, 2020 from https://www.bulatlat.com/2017/06/06/new-school-year-old-problems-k-12-shortages-classrooms-teache $\underline{\mathrm{rs} /}$

UNESCO IICBA Newsletter. (2015). Capacity development of rural teachers in Africa. International Institute for Capacity Building in Africa. Retrieved on March 16, 2021 from http://unesdoc.unesco.org/images/0023/002313/231308e.pdf

Walsh, J., \& Sattes, B. (2005). Quality questioning: Research-based practice to engage every learner. Thousand Oaks, CA: Corwin Press.

Walton-Fisette, J. L. (2010). Getting to know your students: The importance of learning students' thoughts and feelings in Physical Education. Journal of Physical Education Recreation and Dance, 81(71), 1-60.

Weiqi, C. (2007). The structure of secondary school teacher job satisfaction and its relationship with attrition and work enthusiasm. Chinese Education \& Society, 40(5), 17-31.

Yang, M. K. (2006). A critical review of research on questioning in education: limitations of its positivistic basis. Asia Pacific Education Review, 7(2), 195-204.

Zechariah, S. (2002). Teaching: A Meaningful and Challenging Career. Retrieved on September 2, 2021 from https://www.science.org/content/article/teaching-meaningful-and-challenging-career-rev2 